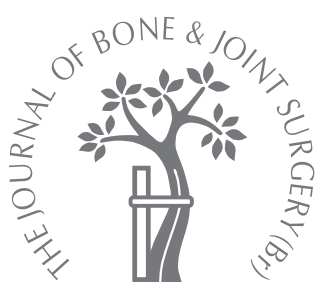

Y. H. Lee, J. Y. Kim, M. S. Chung, G. H. Baek, H. S. Gong, S. K. Lee

From Seoul National University, Seoul, Korea

= Y. H. Lee, MD, PhD, Assistant Professor, Orthopaedic Surgeon

= M. S. Chung, MD, PhD, Professor, Orthopaedic

Surgeon

G. H. Baek, MD, PhD,

Professor, Orthopaedic

Surgeon

H. S. Gong, $\mathrm{MD}, \mathrm{PhD}$

Assistant Professor,

Orthopaedic Surgeon

Department of Orthopaedic

Surgery

Seoul National University,

College of Medicine, 28

Yeonkeon-dong, Chongro-gu,

Seoul 110-744, Korea.

J. Y. Kim, MD, Assistant Professor, Orthopaedic

Surgeon

Department of Orthopaedic

Surgery

Dongguk University College of Medicine Ilsan Hospital, 814

Siksadong, Donggu, Ilsan,

Goyang, Korea.

In. K. Lee, MD, Assistan Professor, Orthopaedic

Surgeon

Department of Orthopaedic

Surgery

Eulji University, College of

Medicine, 1306 Dunsan-dong,

Seo-gu, Daejeon 302-799,

Korea.

Correspondence should be sent to Dr J. Y. Kim; e-mail:

bigjw@naver.com

(C)2009 British Editorial Society of Bone and Joint Surgery doi:10.1302/0301-620X.91B11. $22478 \$ 2.00$

$J$ Bone Joint Surg [Br] 2009;91-B:1478-81. Received 17 February 2009; Accepted after revision 7 July 2009

\title{
Two extension block Kirschner wire technique for mallet finger fractures
}

\author{
We treated 32 displaced mallet finger fractures by a two extension block Kirschner-wire \\ technique. The clinical and radiological outcomes were evaluated at a mean follow-up of \\ 49 months (25 to 84$)$. The mean joint surface involvement was $38.4 \%(33 \%$ to $50 \%)$ and \\ 18 patients $(56 \%)$ had accompanying joint subluxation. \\ All 32 fractures united with a mean time to union of 6.2 weeks (5.1 to 8.2). Congruent joint \\ surfaces and anatomical reduction were seen in all cases. The mean flexion of the distal \\ interphalangeal joints was $83.1^{\circ}\left(75^{\circ}\right.$ to $\left.90^{\circ}\right)$ and the mean extension loss was $0.9^{\circ}\left(0^{\circ}\right.$ to $\left.7^{\circ}\right)$. \\ No digit had a prominent dorsal bump or a recurrent mallet deformity. \\ We believe that this technique, when properly applied, produces satisfactory results both \\ clinically and radiologically.
}

Mallet deformity of the finger involves avulsion of the extensor tendon from the base of the distal phalanx, with or without a bony fragment. Wehbe and Schneider ${ }^{1}$ recommended nonoperative treatment for most mallet fractures and concluded that reduction is not crucial because of bone remodelling. However, others consider that restoration of the joint surface by accurate reduction is important, in order to prevent secondary osteoarthritis, loss of movement, and a poor cosmetic outcome. They advocate operative treatment, especially where the fracture involves more than $30 \%$ of the articular surface ${ }^{2}$ or there is volar subluxation. ${ }^{3-5}$ Although open repair has been proposed, it is technically demanding and liable to complications, which include skin breakdown, infection, loss of reduction, joint stiffness, nail growth deformity, soft-tissue scar formation and avascular necrosis. ${ }^{5}$ Several authors have described percutaneous procedures that permit indirect anatomical reduction of fractures to avoid the disadvantages of the open method. ${ }^{6-9}$ Extension block pinning, which consists of a dorsal extension block Kirschner (K)-wire and a second volar wire to hold the distal interphalangeal joint in extension, was described in 1988 by Ishiguro et al. ${ }^{6}$ This simple and reliable method has been modified by several authors ${ }^{10-12}$ to improve the accuracy of reduction and stability of fixation. We consider that more accurate reduction and stable fixation is achieved when two small extension block K-wires are used, thereby producing a more favourable outcome.
The aim of this study was to describe our refinement of Ishiguro's technique using two small extension block K-wires and to present the outcome in 32 patients.

\section{Patients and Methods}

We reviewed 32 consecutive patients with a mallet fracture of a distal phalanx treated by our modified technique between May 2001 and May 2006. There were 22 males and ten females with a mean age of 28.1 years (17 to 47 ). The indication for operation was a displaced mallet finger fracture involving more than one-third of the articular surface, with or without volar subluxation of the distal phalanx (Figs 1a and 2a). Comminuted or open fractures were excluded. The mean joint surface involvement was $38.4 \%$ (33\% to $50 \%$ ), and 18 patients $(56 \%)$ had associated subluxation. The mean time from injury to operation was 22 days (1 to 22). The mean follow-up was 49 months (25 to 84 ).

The procedure was generally performed under digital block anaesthesia with image intensifier control. With the distal and proximal interphalangeal joints held in maximum flexion, a $0.9 \mathrm{~mm} \mathrm{~K}$-wire is introduced just behind the fragment and driven proximally into the head of the middle phalanx at an angle of $30^{\circ}$ to its long axis. A second $\mathrm{K}$-wire is inserted $2 \mathrm{~mm}$ to $3 \mathrm{~mm}$ apart from and parallel to the first. Closed reduction is achieved by extension of the distal phalanx along with dorsal translation when there is volar subluxation 


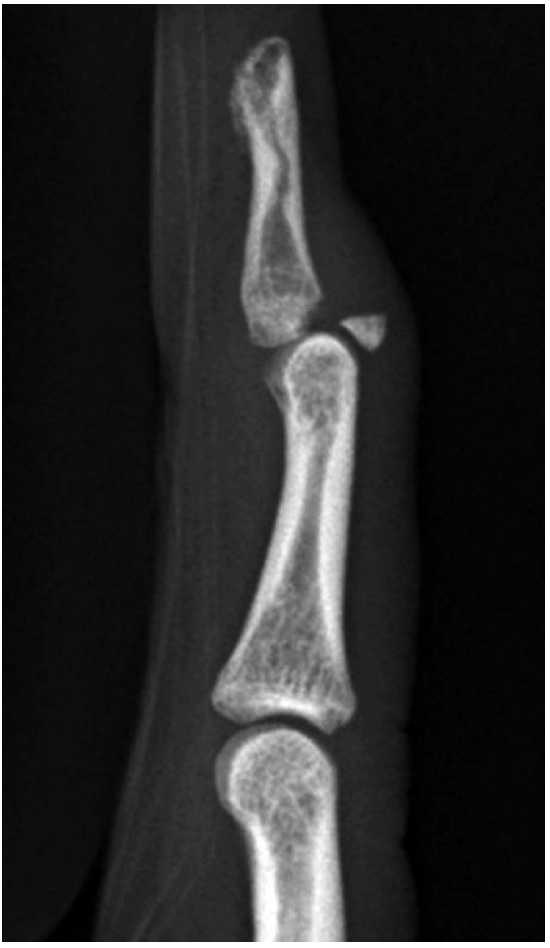

Fig. 1a

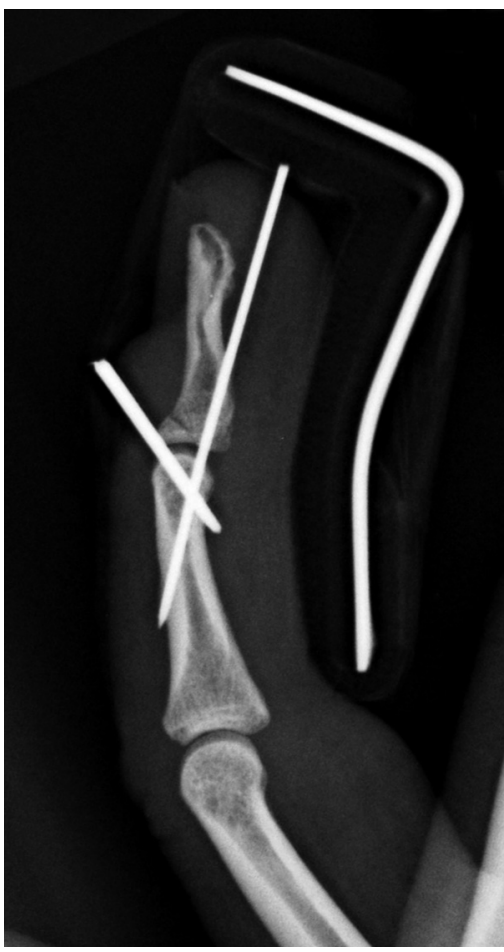

Fig. $1 \mathrm{~b}$

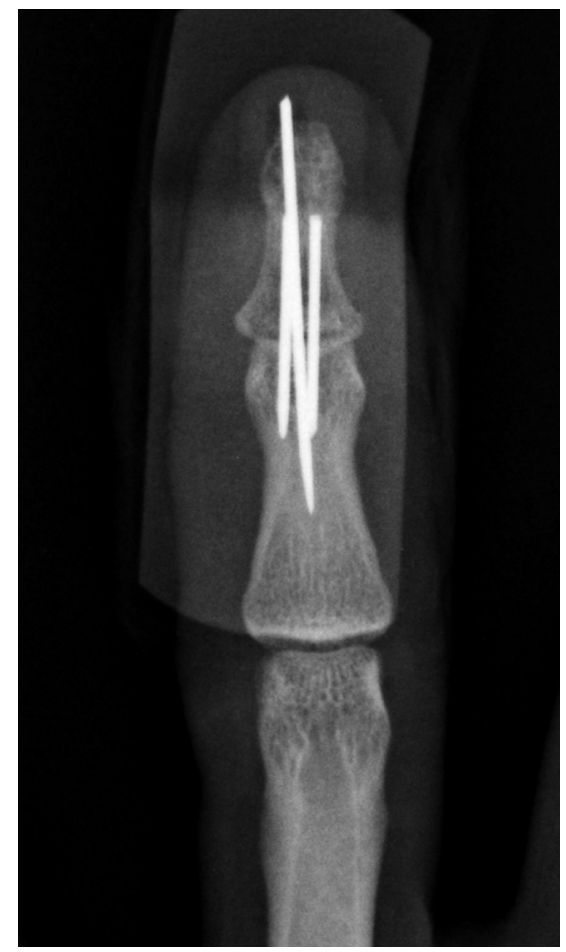

Fig. 1c

A 27-year-old man with a mallet fracture of the ring finger. a) The pre-operative radiograph showed a fracture involving more than one-third of the base of the distal phalanx, with volar subluxation at the distal interphalangeal joint. b) Anatomical reduction with an aluminium splint to protect the wires and block the movement of the distal interphalangeal joint. c) Anteroposterior view.

of the distal phalanx. A third $0.9 \mathrm{~mm} \mathrm{~K}$-wire is inserted from the volar side across the distal interphalangeal (DIP) joint to maintain extension and reduction. The wires are cut short and a volar aluminium splint is applied to protect them and prevent movement of the DIP joint (Figs 1 and $2 b$ and c). Regular dressings and pin care hygiene is encouraged. The wires are removed in outpatients six weeks postoperatively, when bridging trabeculae were seen in radiographs, and the fracture sites were non-tender. After removal of the wires, active exercises of the DIP joint were started. No protective splint was subsequently used.

Radiographs were taken immediately after fixation and at two weeks, six weeks, two months, then every six months after union. The range of active movement was measured with a goniometer at each visit and any complications were documented. Crawford's rating system ${ }^{13}$ was applied to assess outcome (Table I), which was graded as excellent, good, fair or poor.

\section{Results}

All fractures united at a mean time of 6.2 weeks (5.1 to 8.2). Congruent and satisfactory joint surfaces (anatomical or intra-articular step-off of $<1 \mathrm{~mm}$ ) were present in all patients, and no arthritic changes were observed at final follow-up (Fig. 2d). The mean active flexion of the DIP was $83.1^{\circ}\left(75^{\circ}\right.$ to $\left.90^{\circ}\right)$ and the mean loss of voluntary extension was $0.9^{\circ}\left(0^{\circ}\right.$ to $\left.7^{\circ}\right)$ at final follow-up. Nail ridging occurred in three cases but disappeared at a mean eight months (6 to 10) with normal growth. A mild superficial infection at a pin entry site occurred in two cases and settled with regular dressings only. There were also two cases of transient nail deformity. No skin breakdown occurred, but there was mild scarring at a dorsal pin site in one case. No finger had a prominent dorsal bump or recurrent mallet deformity (Figs $2 \mathrm{e}$ and 2f). All patients were satisfied with function and cosmesis. According to Crawford's classification (Table I), the outcome was excellent in $22(68.8 \%)$, good in eight $(25.0 \%)$, and fair in two $(6.2 \%)$ patients. The K-wires were removed at a mean of 44 days (36 to 58) post-operatively.

\section{Discussion}

Ishiguro's method is easier than open surgery and indirect manipulation reduces the possibility of the fragment becoming comminuted. However, when the dorsal fragment is large, markedly displaced or rotated, it is not easily controlled indirectly with a single K-wire.

We have routinely used two parallel extension block pins $2 \mathrm{~mm}$ to $3 \mathrm{~mm}$ apart to achieve better control of the dorsal fragment. The technique of insertion of the wires is similar to that of the original Ishiguro method, but the wires are smaller and are inserted at a lower angle $\left(30^{\circ}\right.$ to the axis of the middle phalanx). Anatomical reduction is obtained more easily with two extension block wires because they create a wall that prevents rotation of even a large fragment when a 


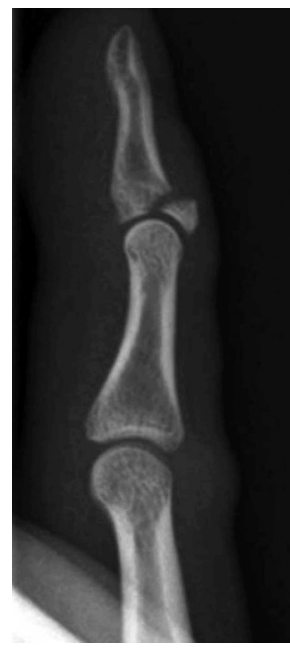

Fig. 2a

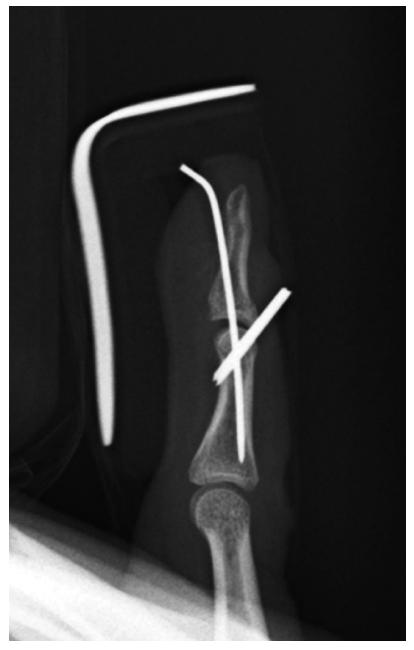

Fig. 2b

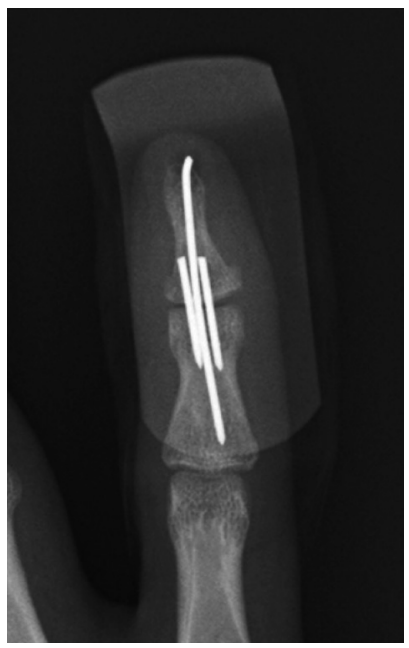

Fig. 2c

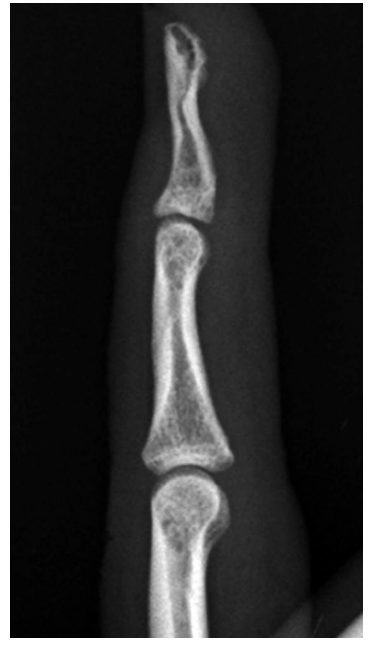

Fig. 2d

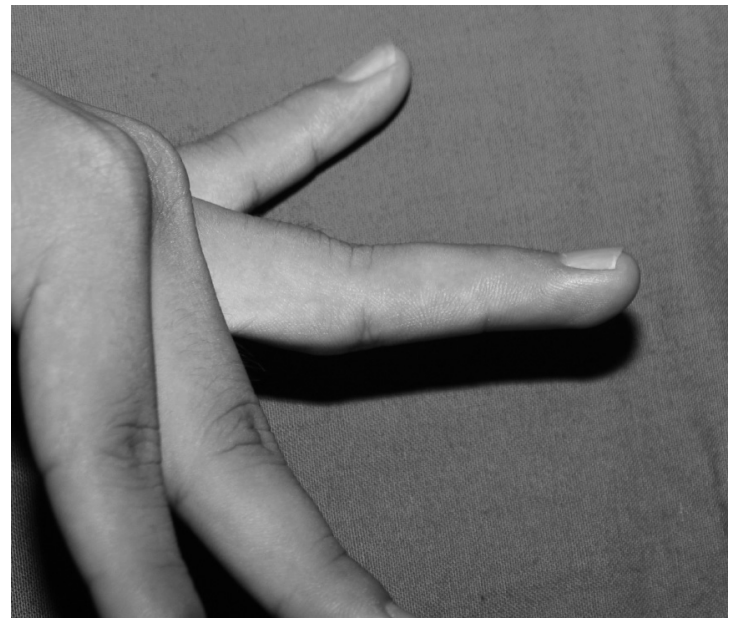

Fig. $2 e$

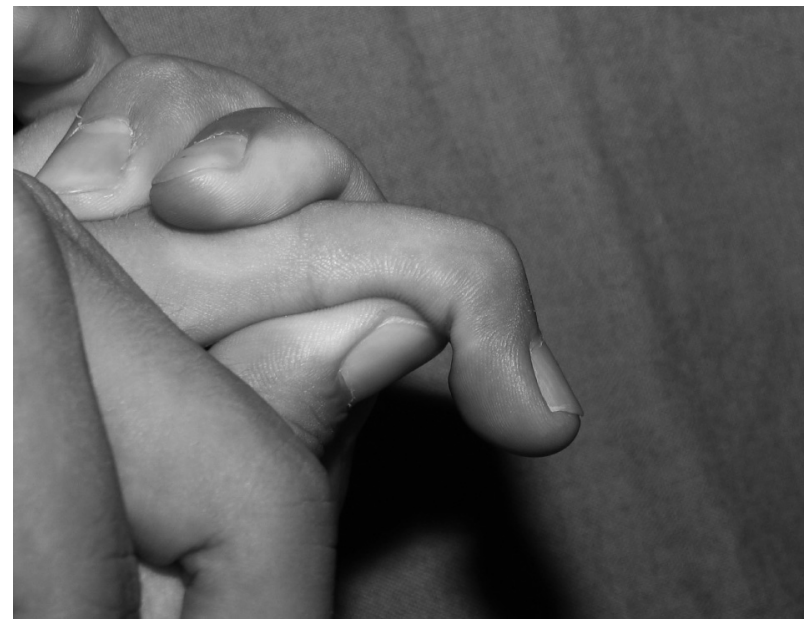

Fig. $2 f$

A 65 -year-old woman with a) a fracture fragment involving $50 \%$ of the articular surface, b) anatomical reduction was achieved and a volar splint applied, c) Anteroposterior view, d) the final follow-up radiographs showed a healed fracture with a congruous joint surface. No arthritis changes were observed and there was full active flexion and extension of the distal interphalangeal joint of the fourth finger was regained. Photographs showing e) lateral view in full extension and f) in full flexion.

Table I. Outcome assessment: Crawford's evaluation criteria ${ }^{13}$

\begin{tabular}{ll}
\hline Excellent & $\begin{array}{l}\text { Full extension, full flexion, no pain, loss of extension } \\
\text { between } 0^{\circ} \text { and } 10^{\circ}\end{array}$ \\
Good & $\begin{array}{l}\text { Full flexion, no pain, loss of extension between } 10^{\circ} \\
\text { and } 25^{\circ}\end{array}$ \\
Fair & Any loss of flexion, no pain, loss of extension $>25^{\circ}$ \\
Poor & Any loss of flexion, persistent pain \\
\hline
\end{tabular}

reduction force is applied. The parallel and lower angled wires make contact with a wide area of the fragment, which is strongly compressed when the distal phalanx is extended, thereby achieving and maintaining a better reduction. Also, the use of smaller wires is less traumatic and reduces pinrelated complications. Anatomical reduction with a comparable range of movement was achieved in all cases. The complications were largely related to difficulties with reduction and fixation. Transient nail ridging occurred after vigorous manipulation or repetitive reduction manoeuvres in patients with volar subluxation of the DIP joint, marked displacement of a fracture fragment or an old fracture (more than three weeks after injury). Dorsal scarring occurred after repeated insertion of the dorsal pin due to a technical error. Therefore, a meticulous reduction technique is as important as careful pinning, especially in patients with an old fracture, marked displacement or palmar subluxation.

In conclusion, we have found that two-extension block Kwires, when correctly applied, produces good radiological and clinical outcomes by achieving anatomical reduction and stable fixation with relatively few complications.

No benefits in any form have been received or will be received from a commercial party related directly or indirectly to the subject of this article. 


\section{References}

1. Wehbe MA, Schneider LH. Mallet fractures. J Bone Joint Surg [Am] 1984;66A:658-69.

2. Hamas RX, Horrell ED, Pierret GP. Treatment of mallet finger due to intraarticular fracture of the distal phalanx. J Hand Surg [Am] 1978;3:361-3.

3. Doyle J. Extensor tendons: acute injuries. In: Green DP, Hotchkiss RN, Pederson WC, eds. Operative hand surgery. Fourth ed. Vol II. Philadelphia: Churchill Livingstone, 1999:1950-70.

4. Jupiter JB, Sheppard JE. Tension wire fixation of avulsion fractures in the hand Clin Orthop 1987;214:113-20.

5. Damron TA, Engber WD. Surgical treatment of mallet finger fractures by tension band technique. Clin Orthop 1994;300:133-40.

6. Ishiguro T, Inoue K, Matsubayashi N, Ito $\mathbf{Y}$, Hashizume N. A new method of closed reduction for mallet fractures. Cent Japan J Orthop Traumatol 1988;31:2049-51.
7. Inoue G. Closed reduction of mallet fractures using extension block Kirschner wire. J Orthop Trauma 1992;6:413-15.

8. Ishiguro T, Itoh Y, Yabe Y, Hashizume N. Extension block with Kirschner wire for fracture dislocation of the distal interphalangeal joint. Tech Hand Up Extrem Surg 1997;1:95-102.

9. Darder-Prats A, Fernandez-Garcia E, Fernandez-Gabarda R, Darder-Garcia A. Treatment of mallet finger fractures by the extension-block K-wire technique. J Hand Surg [Br] 1998;23:802-5.

10. Yamanaka K, Sasaki T. Treatment of mallet fractures using compression fixation pins. J Hand Surg [Br] 1999;24:358-36.

11. Hofmeister EP, Mazurek MT, Shin AY, Bishop AT. Extension block pinning for large mallet fractures. J Hand Surg [Am] 2003;28:453-9.

12. Mazurek MT, Hofmeister EP, Shin AY, Bishop AT. Extension block pinning for treatment of displaced mallet fracture. Am J Orthop 2002;31:652-4.

13. Crawford GP. The molded polythene splint for mallet finger deformities. J Hand Surg Am 1984;9:231-7. 